\title{
Mechanical Properties of Vermicular Graphite Cast Iron Processed by Selective Laser Surface Alloying with Ultra-fine $\mathrm{ZrO}_{2}$ Ceramic Particulates
}

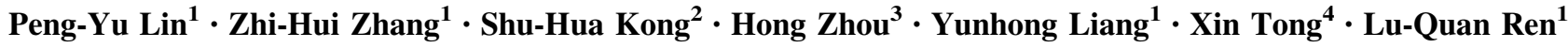

Received: 24 February 2016/Revised: 18 April 2016/Published online: 13 June 2016

(C) The Chinese Society for Metals and Springer-Verlag Berlin Heidelberg 2016

\begin{abstract}
In this work, the mechanical properties and microstructures of vermicular graphite cast iron processed by selective laser surface alloying with ultra-fine $\mathrm{ZrO}_{2}$ ceramic particulates were investigated. A particulate-reinforced metal matrix composite coating with the thickness of $\sim 650 \mu \mathrm{m}$ was fabricated by laser treatment on the sample surface. The particulates were uniformly distributed in the microstructure of the coating. The tensile strength and microhardness both increased with the particulate fraction, since more tensile load was transferred from the matrix to the reinforcement showing essential strengthening effect. The composite coating also sharply reduced the wear mass loss and thus improved the wear resistance.
\end{abstract}

\section{KEY WORDS: Scanning electron microscopy; Mechanical characterization; Magnesium alloys; Grain} refinement; Hardness

\section{Introduction}

Vermicular graphite cast iron (VGCI) is an important structural material. It provides better mechanical properties than the gray cast iron due to the wormlike graphite [1]. The morphologies of the graphite play a major role in affecting

Zhi-Hui Zhang

zhzh@jlu.edu.cn

1 The Key Laboratory of Engineering Bionics (Ministry of Education, China) and the College of Biological and Agricultural Engineering, Jilin University (Nanling Campus), Changchun 130025, China

2 The Department of Weld Planning, FAW-Volkswagen Co. Ltd., Changchun 130011, China

3 The Key Laboratory of Automobile Materials (Ministry of Education, China) and School of Materials Science and Engineering, Jilin University (Nanling Campus), Changchun 130025, China

4 The National Engineering Laboratory for Modern Materials Surface Engineering Technology, Guangzhou Research Institute of Non-ferrous Metals, Guangzhou 510651, China mechanical and physical properties of irons [2]. Thus, the resulting balanced mechanical and physical properties of VGCI promote its applications in manufacturing the brake disks of high-speed trains [3]. In the meanwhile, it is also a preferential material for manufacturing diesel engine blocks. Recent year, the train speed has been increased up to $200-350 \mathrm{~km} / \mathrm{h}$, and moreover, the safety running of the trains and the vehicles has been concerned, and the existing properties of VGCI cannot meet the tougher working conditions, e.g., higher demand on the braking performance (wear) and the better mechanical support for heavier load or higher speed. Therefore, improving its mechanical properties and/or wear resistance is essential for enhancing its use and thus making trains and other vehicles operate safely.

Previous studies have been conducted to improve the properties of steels and irons [4-9]. Zhao et al. [8] studied the optimization of microstructure and mechanical properties of a low-carbon microalloyed cast steel through control of heat treatment conditions. Uematsu et al. [9] reported the role of the carbide in fatigue behavior of highspeed steel and found that the distribution and appearance of the carbide could considerably affect fatigue cracking. 
On the other hand, laser treatment notably results in modification of alloy microstructure and thus improves related properties [3, 10-13]. Our previous studies $[3,10,11]$ reported the mechanical properties and wear resistance of generally used steels processed by laser. As the matter of fact, laser is generally used to fabricate protective/defensive surface layer in order to improve requiring properties of the material such as wear and fatigue. Kulka et al. [13] applied laser boriding to form boride coating on $41 \mathrm{Cr} 4$ steel surface, and it was shown that, under the high abrasive wear condition, laser boriding is preferable to traditional treatment.

In general, laser could modify the surface in a certain depth [3]. So it is good for the surface-related applications [12], such as the wear performance of VGCI. With laser surface alloying (LSA), alloying materials are added into the original surface microstructure, thus leading to the surface strengthening [14]. In general, the major alloying additions are metallic powders, such as $\mathrm{Ni}, \mathrm{Cr}$, and rare earth elements. This is because these metallic additions can form the carbides due to laser treatment, which is a major strengthening mechanism for iron. Recently, ceramic particulates used to fabricate metal matrix composites (MMCs) are also used as additions for laser treatment. As compared to the traditional alloys, MMCs provide superior mechanical properties [13]. Some studies [15, 16] used $\mathrm{ZrO}_{2}$ to strengthen the ZA27 and A356 alloys, respectively. As a result, both the strength and ductility were improved simultaneously. However, that has rarely been studied on VGCI in this manner.

Therefore, here we studied the mechanical properties and wear resistance of VGCI processed by LSA, providing some useful information about its applications. We added $\mathrm{ZrO}_{2}$ ceramic particulates as the alloying material to fabricate the $\mathrm{MMC}$ reinforcement layer on the surface of VGCI using laser treatment.

\section{Materials and Methods}

In this study, VGCI is the base material with the chemical compositions (wt\%) of $3.52 \mathrm{C}, 2.59 \mathrm{Si}, 0.65 \mathrm{Mn}, 0.03 \mathrm{P}$, $0.03 \mathrm{~S}, 0.02 \mathrm{Mg}$, and $\mathrm{Fe}$ in balance. Before LSA treatment, it was cut into the size of $35 \mathrm{~mm} \times 17.5 \mathrm{~mm} \times 6 \mathrm{~mm}$, using an electro-discharge machine. After laser treatment, the samples were ultrasonically cleansed.

The LSA treatment was carried out using a Nd:YAG pulsed laser (JHM-1GY-300B, China). All samples for LSA were referred to as LSA samples. The treatment parameters were constant for the LSA samples and were as follows: the output power of $300 \mathrm{~W}$, the frequency of $8 \mathrm{~Hz}$, and the scanning speed of $0.5 \mathrm{~mm} / \mathrm{s}$, respectively.
Our previous studies [10, 11, 17-19] have developed the biomimetic scanning design for laser treatment, by mimicking the surface morphologies of some creatures, such as the shells, dragonflies, and beetles, which develop the naturally developed surfaces. Therefore, a kind of the selective laser treatment was developed: Only a part of the sample surface is treated. The treated area, in the shapes of stripes, networks, and spots, is uniformly distributed on the sample surface. Here, the LSA samples were treated in networks. The angle between the two treatment directions is $90^{\circ}$. The spacing between every two parallel stripes is $2 \mathrm{~mm}$. It is engineered to mimic the distribution of leaf veins, which provide essential load support for the entire leaves. Figure 1 shows the schematic of this treatment.

The surface alloying material is the blend of the Febased alloying powder (FAP) and the $\mathrm{ZrO}_{2}$ ceramic particulates with the particle size of $\sim 800 \mathrm{~nm}$. Five fractions (wt $\%$ ) of $\mathrm{ZrO}_{2}$ were used: 5, 10, 15, 20, and $25 \mathrm{wt} \%$, respectively, and FAP in balance. The chemical compositions (wt\%) of FAP are as follows: $0.5 \mathrm{C}, 1.5 \mathrm{~B}, 2.5 \mathrm{Si}, 13 \mathrm{Cr}$, $35 \mathrm{Ni}, 5.0 \mathrm{Mo}$, $\mathrm{Co}$ and $\mathrm{Fe}$ in balance.

Microhardness test was performed on a Knoop and Vickers Hardness Table (USA), under the load of $25 \mathrm{~g}$. Each value is an average of six individual measurements. The MTS Hydraulic Servo Testing System (USA) was used for tensile test with a strain rate of $1 \mathrm{~mm} \mathrm{~min}^{-1}$. In addition, wear test was performed against a rotating No. 45 steel plate $(50 \mathrm{~mm}$ in diameter, and with a hardness of 600 $\mathrm{HV}$ ), under the working load of $10 \mathrm{~kg}$. The rotation speed

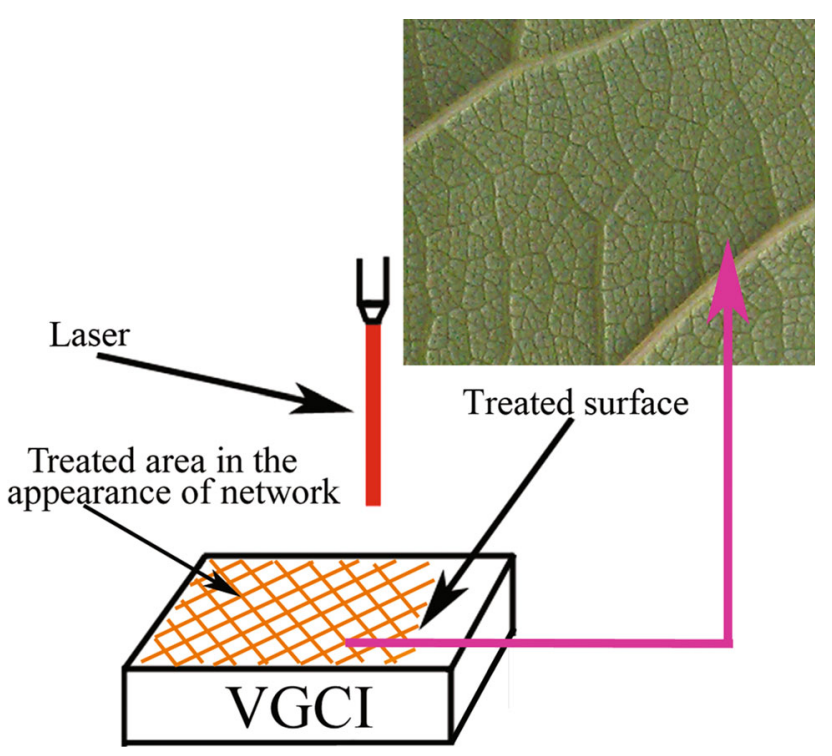

Fig. 1 Schematic of the selective LSA processing 

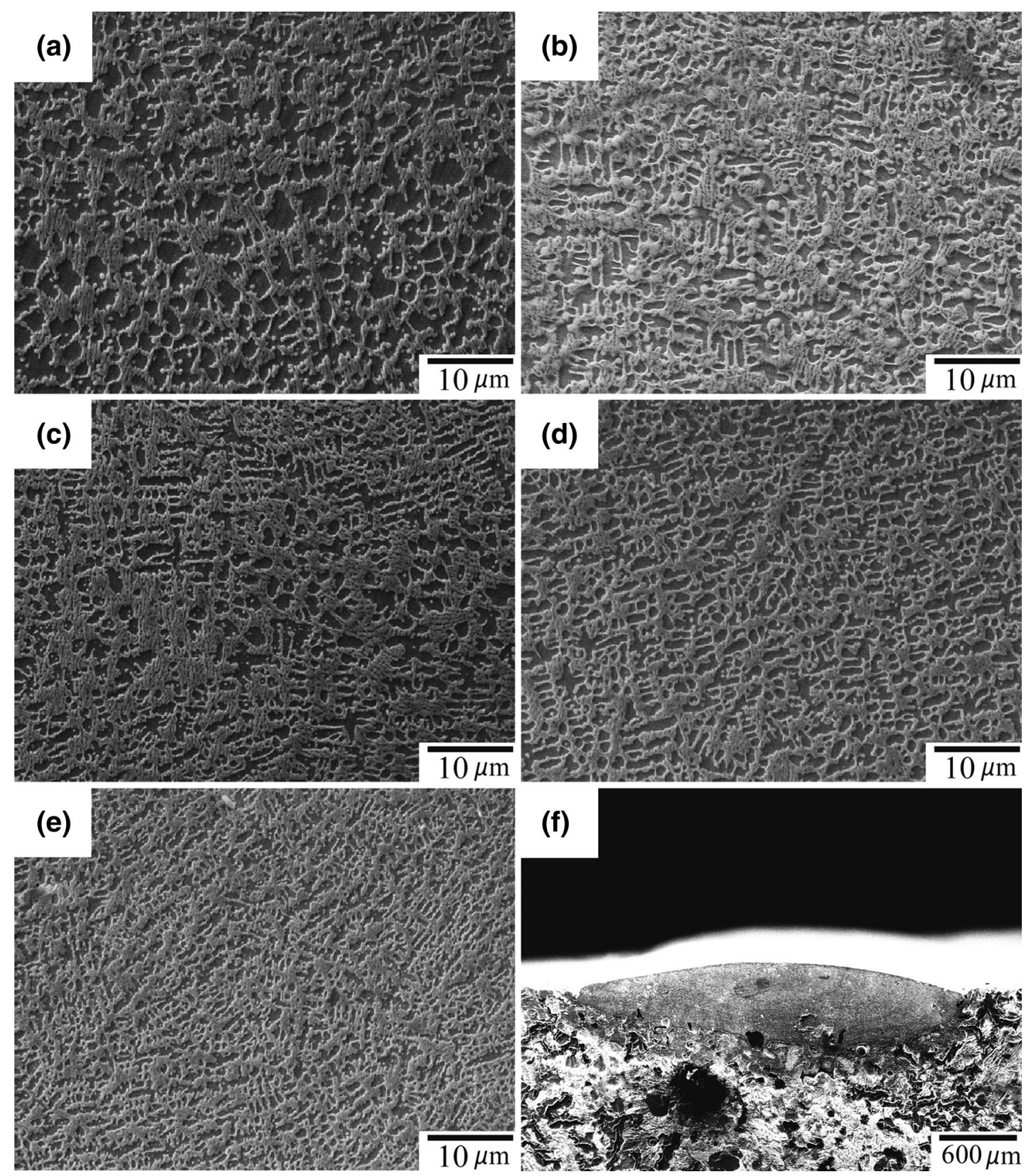

Fig. 2 SEM images of all LSA samples with different $\mathrm{ZrO}_{2}$ fractions. The plain-view SEM images of the treated zones with: a 5 wt $\% \mathrm{ZrO}$, b 10 wt $\% \mathrm{ZrO}_{2}$, c $15 \mathrm{wt} \% \mathrm{ZrO}_{2}$, d $20 \mathrm{wt} \% \mathrm{ZrO}_{2}$, and e $25 \mathrm{wt} \% \mathrm{ZrO}_{2}$. f cross-sectional SEM image of the LSA sample

was $400 \mathrm{rpm}$, and the sliding duration was $30 \mathrm{~min}$. The wear mass loss data are collected for analyzing the resistance to wear of the all samples. Plain-view and crosssectional microstructures were characterized by X-ray diffraction (XRD), field emission scanning electron microscopy (FESEM, JSM-6700F, Japan) equipped with energy-dispersive spectrometer (EDS), and high-resolution transmission electron microscopy (HRTEM, JEOL-2100F, Japan).

\section{Results}

Figure 2 illustrates the SEM images of the treated zones with different $\mathrm{ZrO}_{2}$ fractions. It can be seen that the ceramic particulates uniformly distribute in the matrix, and the microstructure is refined well. The average size of the graphite is smaller. Figure $2 \mathrm{f}$ shows the cross-sectional SEM image of the LSA sample. The treatment depth of $\sim 600 \mu \mathrm{m}$ is acquired. As compared to the original 


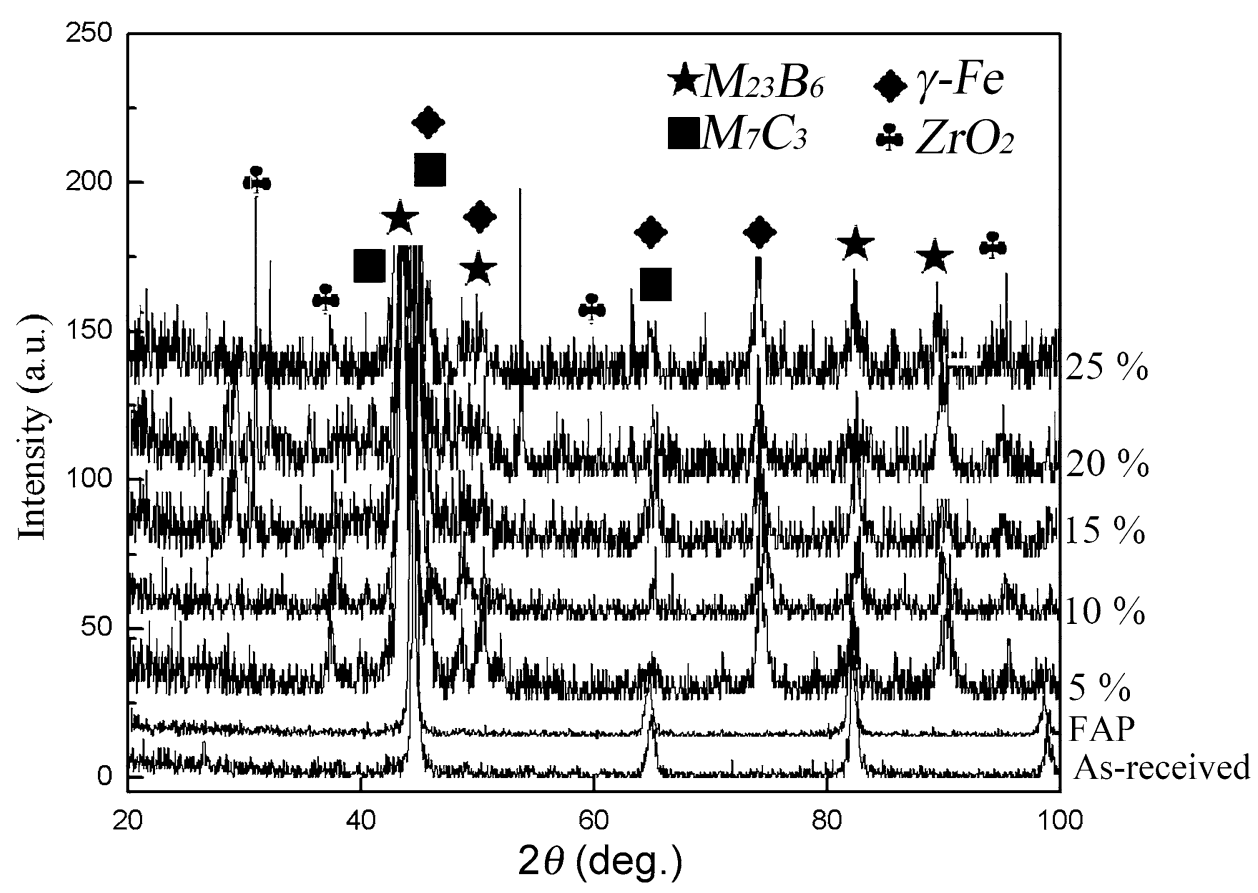

Fig. 3 XRD patterns of the samples with different fractions of $\mathrm{ZrO}_{2}$

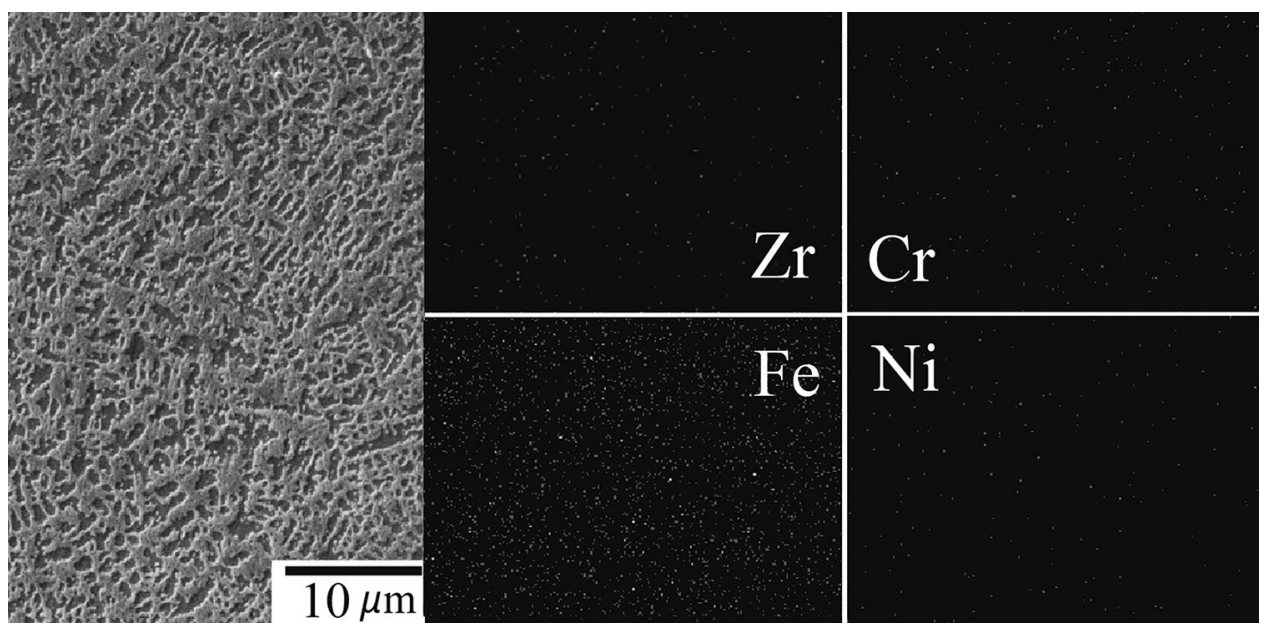

Fig. 4 Elemental distribution of the treated zone obtained by EDS. Only one sample with $25 \mathrm{wt} \% \mathrm{ZrO}_{2}$ was examined on the surface, showing four elements of $\mathrm{Zr}, \mathrm{Cr}, \mathrm{Ni}$, and $\mathrm{Fe}$

microstructure beneath the treated area, the LSA counterpart is notably refined, with the all $\mathrm{ZrO}_{2}$ fractions.

Figure 3 shows the XRD pattern of the samples with different fractions of $\mathrm{ZrO}_{2}$. Note that there are no other $\mathrm{Zr}$ based compounds formed during LSA. In addition, due to adding other alloying elements, e.g., $\mathrm{C}$ and $\mathrm{B}$ related compounds formed as well.

Figure 4 shows the elemental distribution of the major alloying elements in the treated zone determined by EDS shown in Fig. 2e. Four elements, $\mathrm{Zr}, \mathrm{Cr}, \mathrm{Ni}$, and $\mathrm{Fe}$, were examined simultaneously. As it is shown, all alloying elements are uniformly distributed on the surface, indicating that the $\mathrm{ZrO}_{2}$ particulates and the other precipitates are uniformly distributed in the treated zone.

Figure 5 shows the HRTEM image of the treated zone. The $\mathrm{ZrO}_{2}$ particulate is present. It is observed that tangled dislocation is clearly around the ceramic particle because of different contrasts between the ceramic particle and matrix expansion. The rapid solidification of liquid metal will induce dislocation along the boundaries 
between the particles and the matrix. They worked as refiner to strengthen the matrix further. Therefore, the more $\mathrm{ZrO}_{2}$ is used, the better the properties are in this way.

Figure 6 gives the mechanical properties of all samples as a function of the $\mathrm{ZrO}_{2}$ fraction. Figure 6a shows that the microhardness of the treated zone was increased with the amount of $\mathrm{ZrO}_{2}$. So the LSA sample with $25 \mathrm{wt} \% \mathrm{ZrO}_{2}$ gives the highest microhardness. In the meanwhile, the strengthened depth was near $800 \mu \mathrm{m}$ in Fig. 6a. For the LSA samples, the microhardness was sharply reduced reaching the original microstructure. On the other hand, as shown in Fig. 6b, LSA samples exhibit the better mechanical properties than the as-received counterparts. The FAP leads to a notable improvement in microhardness, and UTS and YS, simultaneously (see the results with 0 wt $\% \mathrm{ZrO}_{2}$ ). Due to adding the $\mathrm{ZrO}_{2}$ particles, the properties are further enhanced with the increase in the $\mathrm{ZrO}_{2}$

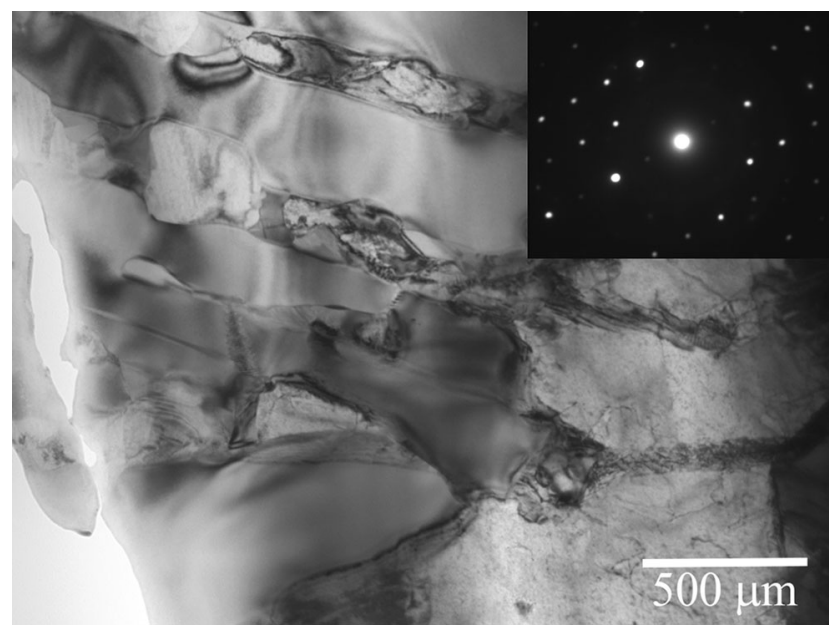

Fig. 5 HRTEM of the treated zone

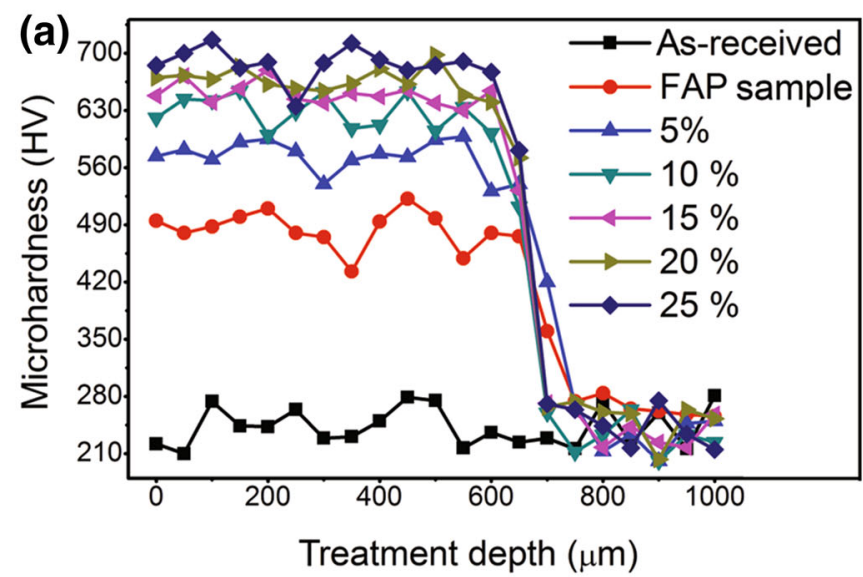

fraction, the best one of all achieved for the sample with 25 wt $\% \quad \mathrm{ZrO}_{2}: \sim 680 \quad(\mathrm{HV}), \sim 670 \mathrm{MPa}$ (UTS), and $\sim 530 \mathrm{MPa}$ (YS), respectively. On the other hand, EL is mildly decreased with the increasing particulate fraction, which was considered as a sensible compromise for the improvement in strength.

Figure 7 plots the accumulative wear loss curves of the all samples laser treated, within $30 \mathrm{~min}$. It shows that as the $\mathrm{ZrO}_{2}$ fraction increases, the wear loss is dramatically decreased. The LSA sample, with $25 \mathrm{wt} \% \mathrm{ZrO}_{2}$, exhibits the smallest wear loss of all. In contrast, the as-received sample exhibits a much larger wear loss than the all LSA counterparts. As compared to the as-received sample, the FAP counterpart possessed a much better wear resistance with over $50 \%$ less of the wear mass loss. Moreover, the addition of $\mathrm{ZrO}_{2}$ furthered this improvement. The wear mass loss of the sample with $25 \mathrm{wt} \% \mathrm{ZrO}_{2}$ is only $\sim 1 / 7$ that of the as-received sample.

\section{Discussion}

In general, pure iron exhibits good strength [20]. However, irregular graphite in the matrix is detrimental to the properties, because the graphite has no strength, and moreover, cracking takes place at sharp corners and formed the terminal of the graphites due to severe stress concentration. The lamellar graphite of high aspect ratio can promote cracking and thereby lead to the fracture of the graphites [21].

FAP ( $0 \mathrm{wt} \% \mathrm{ZrO}_{2}$ ) led to notable improvements in microhardness, UTS, and YS. The tensile properties were enhanced by the dominantly martensitic microstructure. This martensitic microstructure possesses superior strength [22]. It derived from self-quenching of laser processing.

Fig. 6 Variations in the microhardness, UTS, YS and EL with the particle fraction of the all samples: a microhardness profiles. The measurement direction is perpendicular from the sample surface to the internal; b UTS, YS and EL curves 
During the remelting of the treated area, the alloying elements melted into solid solution. Furthermore, carbides formed. These microstructural modifications greatly contributed to the improvement of the mechanical properties [23].

It is interesting to note that the mechanical properties were further improved by adding the $\mathrm{ZrO}_{2}$ particulates. Via laser alloying, a particulate-reinforced composite layer was introduced on the sample surface. Therefore, UTS was increased up to $>600 \mathrm{MPa}$ when the fraction was $25 \mathrm{wt} \%$. During tensile test, fracture was mainly caused by interdendritic cracking due to stress concentration. However, reinforcing the matrix with $\mathrm{ZrO}_{2}$ particulates could reduce or retard cracking during loading: The load can be transferred from the matrix crossing the particulate/matrix interface to the $\mathrm{ZrO}_{2}$ particulates [24]. Figure 5 presents a large amount of dislocation around the $\mathrm{ZrO}_{2}$ particulates which are uniformly distributing in the matrix. These characteristics significantly increased the tensile strength. In the meanwhile, increasing the $\mathrm{ZrO}_{2}$ fraction is favorable to the transition, resulting in the higher tensile strength and microhardness. On the other hand, since the graphite has extremely low strength, the laser treatment decreases the amount of the graphite (see Fig. 2f), which also contributed to the higher strength of the LSA sample.

The stress concentration usually formed the particulate/matrix interface or the sharp corners of the particulates [25]. It is thereby detrimental to elongation. As shown in Fig. $6 \mathrm{~b}$, the EL was decreased with increasing particle fraction. This is because the more particulates, the more void nucleation sites, leading to cracking easy. Chawla and Shen [23] reported a more obvious decrease in EL at higher particulate fraction. In present work, the EL is mildly decreased. On the other hand, note that the martensitic

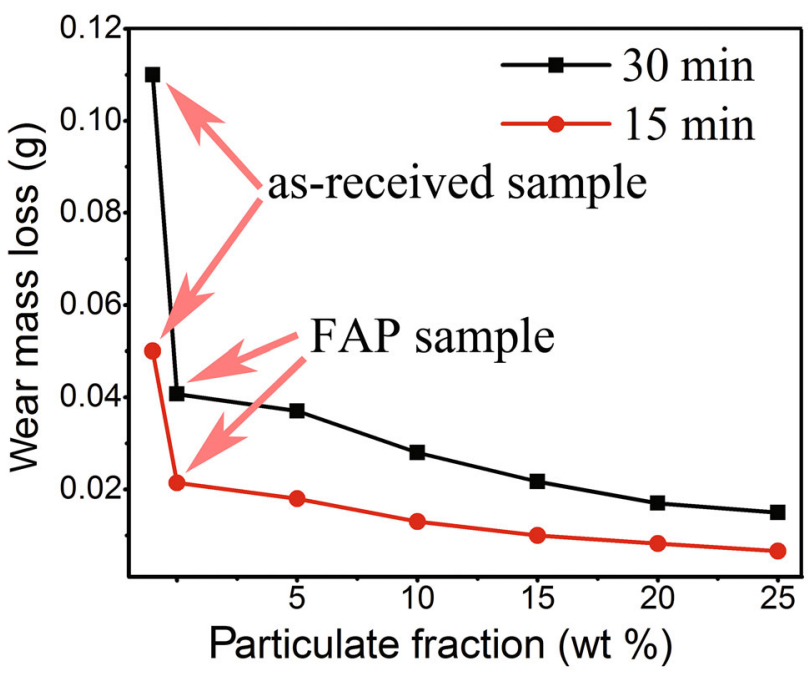

Fig. 7 Accumulative wear mass loss as a function of the $\mathrm{ZrO}_{2}$ fraction. Wear test for $30 \mathrm{~min}$ was conducted for all samples microstructure induced by laser treatment is detrimental to ductility [22]. The difference might be due to the less amount of the irregular graphite (Fig. 2f) and notable grain refinement, which could slightly compensate the reduced ductility. A similar case was reported by Mazaheri et al. [5]. They found that although a martensitic microstructure was created, but much smaller grain size and presence of small size carbides led to high strength $(60 \%$ higher than original) without significant loss of ductility.

In general, the tensile failure is caused by matrix cracking. Stress concentration is usually formed at the sharp corner of the graphite terminal and thereby promotes cracking, also known as the notch effect [26]. Since the amount of the "wormlike" graphite is decreased in the matrix, the cracking is markedly curbed accordingly. $\mathrm{Li}$ et al. [27] reported different types of fracture in MMCs such as matrix cracking and particulate fracture which might simultaneously contribute to the fracture of the LSA samples also. One can thus anticipate that the microstructural cracking mainly took place at the sharp corners of the ceramic particulates and carbides.

The microhardness curves of the treated zone of the all LSA samples are demonstrated in Fig. 6a. In general, the microhardness of treated zone increased with the amount of $\mathrm{ZrO}_{2}$. As only FAP was alloyed on the sample surface, the microhardness was notably increased due to aforementioned mechanisms led by laser $[9,10,20,21]$. Due to the presence of $\mathrm{ZrO}_{2}$, the improvement in the mechanical properties was promoted. The amount of $25 \mathrm{wt} \% \mathrm{ZrO}_{2}$ possessed highest microhardness in this work. On the other hand, there existed some abrupt decrease in microhardness in the treated zone. It could be caused by laser-led porosity, tiny-size graphite, and other reasons (see Fig. 2f). However, it had limited effect on the average microhardness and the strengthening effects in the treated zone.

The wear mass loss of the LSA sample was markedly reduced. This is because the microhardness of the LSA sample was much higher than that of the as-received counterpart, according to the Archard's equation [28]. Figure 8 shows the worn surface morphologies of the all samples. Figure 8a presents the worn surface of the asreceived sample. The contact surface was badly damaged. The surface was characterized by the deep grooves and cracks. However, for the LSA samples, the treated area exhibited smoother surface than the untreated counterpart. As the fraction of $\mathrm{ZrO}_{2}$ increased, the accumulative wear loss is reduced. The composite coating with higher fraction of $\mathrm{ZrO}_{2}$ has more effect of protection. Furthermore, the material in the contact area also played a role in damaging the contact surface, in particular the graphite area. Due to high microhardness and the presence of $\mathrm{ZrO}_{2}$, the treated zone can hold load transfer and thereby reduce wear mass loss and/or wear rate [29]. In addition, there was little 

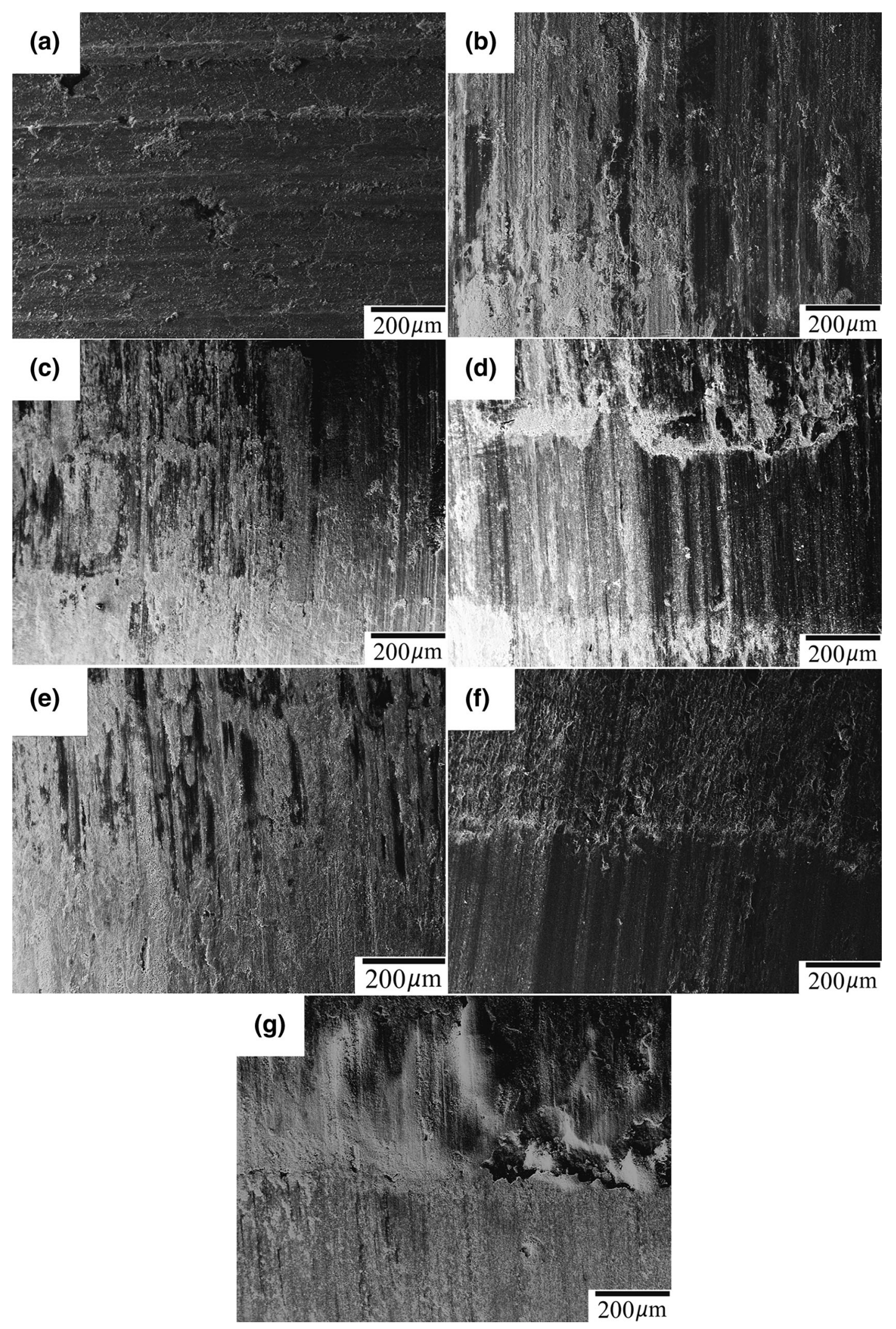

Fig. 8 Morphologies of the worn surface of all samples: a as-received sample, b FAP, c $5 \mathrm{wt} \%$, d $10 \mathrm{wt} \%$, e $15 \mathrm{wt} \%$, f $20 \mathrm{wt} \%$, g $25 \mathrm{wt} \%$ 
irregular graphite after laser treatment. Cracking was difficult in the treated zone. Even if wear crack reached the treated zone, it was much harder to penetrate/propagate between the treated zone and the matrix due to the high microhardness.

As aforementioned, the FAP sample already possessed better wear resistance. The accumulative wear mass loss (see Fig. 7) shows that the FAP notably enhanced the wear resistance. The wear mass loss was reduced by $>50 \%$. Even without $\mathrm{ZrO}_{2}$ particulates, the nature of laser treatment in this work generated many strengthening particles, leading to other strengthening/hardening effect further. On the other hand, presence of $\mathrm{ZrO}_{2}$ particulates encouraged the improvement in wear resistance due to formation of the composite coating. More $\mathrm{ZrO}_{2}$ could withstand more wear load. So the wear mass loss was even lower than that with FAP. We see that the increase in wear loss was curbed by $\mathrm{ZrO}_{2}$ as wear test progressed. However, the wear loss of the as-received sample was increased.

\section{Conclusions}

In the present study, the ultra-fine $\mathrm{ZrO}_{2}$ particulates with different fractions were used to improve the mechanical properties and wear resistance of VGCI by means of LSA. As a result, a composite coating was formed on the sample surface. The thickness is about $600 \mu \mathrm{m}$. The surface microstructure was greatly modified. As inferred from the EDS, the $\mathrm{ZrO}_{2}$ particulates are uniformly distributed in the matrix.

The mechanical properties were effectively improved due to formation of the composite layer. The microhardness was increased up to $680 \mathrm{HV}$. This is because the tensile load was transferred from the matrix to the reinforcement. On the other hand, the ductility was not apparently decreased. The grain refinement is also a notable contributor to the overall improvement in the properties. The decrease in the amount of the graphite in the original microstructure contributes to the higher strength and curbs cracking.

In addition, the $\mathrm{ZrO}_{2}$ particulates markedly improved wear resistance due to the increase in microhardness and, on the other hand, the decrease in the graphite in the microstructure. The LSA surface demonstrates better worn morphology than the as-received sample, leading to the decline in the mass loss.

Acknowledgments This work was supported by Project 985-Bionic Engineering Science and Technology Innovation of Jilin University, the National Natural Science Foundation for Youths (No. 51205160), and the Pearl River S\&T Nova Program of Guangzhou (No. 2014J2200095).

\section{References}

[1] H. Zhou, Q.C. Guo, P.Y. Lin, W. Zhang, X.L. Zhang, L.Q. Ren, Appl. Surf. Sci. 255, 3394 (2008)

[2] M. Hatate, T. Shiota, N. Takahashi, K. Shimizu, Wear 251, 885 (2001)

[3] H. Zhou, L. Chen, W. Wang, L.Q. Ren, H.Y. Shan, Z.H. Zhang, Mater. Sci. Eng., A 412, 323 (2005)

[4] J.Y. Park, Y.S. Ahn, Acta Metall. Sin. (Engl. Lett.) 28, 32 (2015)

[5] Y. Mazaheri, A. Kermanpur, A. Najafizadeh, N. Saeidi, Acta Metall. Sin. (Engl. Lett.) 28, 249 (2015)

[6] B. Han, L. Chen, S.J. Wu, Acta Metall. Sin. (Engl. Lett.) 28, 614 (2015)

[7] K. Zhang, Z.D. Li, X.J. Sun, Q.L. Yong, J.W. Yang, Y.M. Li, P.L. Zhao, Acta Metall. Sin. (Engl. Lett.) 28, 641 (2015)

[8] J.W. Zhao, J.H. Lee, Y.W. Kim, Z.Y. Jiang, C.S. Lee, Mater. Sci. Eng., A 559, 427 (2013)

[9] Y. Uematsu, T. Kakiuchi, K. Tokaji, K. Nishigaki, M. Ogasawara, Mater. Sci. Eng., A 561, 386 (2013)

[10] Z.H. Zhang, L.Q. Ren, H. Zhou, X. Tong, Chin. Sci. Bull. 54, 584 (2009)

[11] Z.H. Zhang, L.Q. Ren, L. Ren, X. Tong, H.Y. Shan, L. Liu, Int. J. Fatigue 31, 468 (2009)

[12] Z.H. Zhang, H. Zhou, L.Q. Ren, X. Tong, H.Y. Shan, Y. Cao, Appl. Surf. Sci. 253, 8939 (2007)

[13] M. Kulka, N. Makuch, A. Pertek, Opt. Laser Technol. 45, 308 (2013)

[14] X. Tong, M.J. Dai, Z.H. Zhang, Appl. Surf. Sci. 271, 373 (2013)

[15] M.T.A. El-khair, A. Lotfy, A. Daoud, A.M. El-Sheikh, Mater. Sci. Eng., A 528, 2353 (2011)

[16] H. Abdizadeh, M.A. Baghchesara, Ceram. Int. 39, 2045 (2013)

[17] Z.H. Zhang, L.Q. Ren, T. Zhou, Z.W. Han, H. Zhou, L. Chen, Y. Zhao, J. Bionic Eng. 7, 67 (2010)

[18] H. Zhou, Z.H. Zhang, L.Q. Ren, Q.F. Song, L. Chen, Surf. Coat. Technol. 200, 6758 (2006)

[19] P.Y. Lin, Z.H. Zhang, H. Zhou, L.Q. Ren, Mater. Sci. Eng., A 560, 627 (2013)

[20] Y. Yan, Y. Qi, Q.W. Jiang, X.W. Li, Acta Metall. Sin. (Engl. Lett.) 28, 531 (2015)

[21] M. Bazdar, H.R. Abbasi, A.H. Yaghtin, J. Rassizadehghani, J. Mater. Process. Technol. 209, 1701 (2009)

[22] K. Zhang, P. Liu, W. Li, Z.H. Guo, Y.H. Rong, Acta Metall. Sin. (Engl. Lett.) 28, 1264 (2015)

[23] J.J. Cui, H.Y. Zhang, L.Q. Chen, H.Z. Li, W.P. Tong, Acta Metall. Sin. (Engl. Lett.) 27, 476 (2014)

[24] N. Chawla, Y.L. Shen, Adv. Eng. Mater. 3, 357 (2001)

[25] N. Chawla, C. Andres, J.W. Jones, J.E. Allison, Scr. Mater. 38, 1596 (1998)

[26] W. Lu, Cast Iron and Smelting, 1st edn. (Beijing Mechanical Industry Press, Beijing, 1981)

[27] Y.L. Li, K.T. Ramesh, E.S.C. Chin, Mater. Sci. Eng., A 371, 359 (2004)

[28] J.F. Archard, J. Appl. Phys. 24, 981 (1953)

[29] L. Zhou, G. Liu, Z. Han, K. Lu, Scr. Mater. 58, 445 (2008) 